\title{
Augmented Hippocampal Ripple Oscillations in Mice with Reduced Fast Excitation onto Parvalbumin-Positive Cells
}

\author{
Attila Rácz, ${ }^{\star}$ Alexey A. Ponomarenko, ${ }^{\star}$ Elke C. Fuchs, and Hannah Monyer \\ Department of Clinical Neurobiology, University Hospital of Neurology, 69120 Heidelberg, Germany
}

Generation of fast network oscillations in the hippocampus relies on interneurons, but the underlying specific synaptic mechanisms are not established. The excitatory recruitment of fast-spiking interneurons during hippocampal sharp waves has been suggested to be critical for the generation of $140-200 \mathrm{~Hz}$ ("ripple") oscillations in the CA1 area. To directly test this, we used genetically modified mice (PV- $\Delta$ GluR-A) with reduced AMPA receptor-mediated excitation onto parvalbumin (PV)-positive interneurons and studied hippocampal oscillations in freely moving animals. In PV- $\Delta$ GluR-A mice, ripple-amplitude and associated rhythmic modulation of pyramidal cells and fast-spiking interneurons were increased. These changes were not accompanied by concurrent alterations of firing rates. Neither theta nor gamma oscillations displayed marked alterations in the mutant. These results provide evidence that fast excitation from pyramidal cells to PV-positive interneurons differentially influences ripple and gamma oscillations in vivo.

Key words: AMPA receptors; gamma oscillations; sharp waves; interneurons; burst discharge; synchronization

\section{Introduction}

Hippocampal interneurons play a critical role in the coordination of network activity. The hippocampus comprises a vast interneuron repertoire, and a quite detailed view has emerged regarding the versatility of these cells (for review, see Freund and Buzsáki, 1996; McBain and Fisahn, 2001; Klausberger and Somogyi, 2008). The discharge of specific interneuron subtypes is correlated with the field activity in different frequency bands in vivo (Buzsáki et al., 1992; Penttonen et al., 1998; Csicsvari et al., 1999b; Klausberger et al., 2003) and in hippocampal slices (Mann et al., 2005), suggesting that they play a major role in the generation of these patterns. Parvalbumin (PV)-positive cells comprise $\sim 25 \%$ of hippocampal interneurons and include basket, axo-axonic, and bistratified cells (for review, see Freund and Buzsáki, 1996). Basket cells and axo-axonic cells innervate perisomatic domains, thus controlling the output of hippocampal pyramidal cells, and are considered to play a key role in shaping synchronous network patterns. However, many aspects regarding the mechanisms of interneuron recruitment during distinct forms of network oscillations and the functional consequences for synchronous network activity in freely behaving animals have remained unresolved.

The hippocampus displays a wide range of periodic synchronous network patterns expressed as local field potential (LFP) oscillations. In behaving rodents, theta rhythm $(5-10 \mathrm{~Hz})$ con-

Received 0ct. 21, 2008; revised Jan. 13, 2009; accepted Jan. 30, 2009.

A.R. was supported by Heidelberg University Grant GC791. H.M. was supported by the Schilling Foundation and the Deutsche Forschungsgemeinschaft (Leibniz Award). We thank Drs. Peter H. Seeburg and Rolf Sprengel for providing the "floxed" GluR-A mice and Andriy Sergiyenko and Ulla Amtmann for expert technical assistance.

${ }^{*}$ A.R. and A.A.P. contributed equally to this work.

Correspondence should be addressed to Hannah Monyer, Department of Clinical Neurobiology, University Hospital of Neurology, Im Neuenheimer Feld 364,69120 Heidelberg, Germany. E-mail: monyer@urz.uni-heidelberg.de. DOI:10.1523/JNEUROSCI.5036-08.2009

Copyright $\odot 2009$ Society for Neuroscience $\quad$ 0270-6474/09/292563-06\$15.00/0 current with gamma oscillations $(30-85 \mathrm{~Hz})$ is characteristic for awake exploration and paradoxical sleep (PS), whereas highfrequency oscillations (140-200 Hz, "ripples") (O'Keefe and Nadel, 1978; Buzsáki et al., 1992) occur during slow-wave sleep (SWS) and consummatory behaviors. Network oscillations have been implicated in a number of cognitive processes (Gray and Singer, 1989; Fries et al., 2002), especially in learning and memory (Buzsáki, 1989; Buzsáki et al., 1994; Wilson and McNaughton, 1994; Jensen and Lisman, 1996; Kudrimoti et al., 1999). Fast hippocampal oscillations are thought to arise from the dynamic interactions between large populations of pyramidal cells and interneurons (Traub et al., 1998; Csicsvari et al., 1999b, 2000, 2003). In particular, excitatory transmission from principal cells onto interneurons has been suggested to be involved in the network mechanism of fast oscillations (Ylinen et al., 1995; Csicsvari et al., 1999b, 2000; Fuchs et al., 2007). Here we studied hippocampal network oscillations in behaving mice with genetically reduced AMPA receptor-mediated glutamatergic innervation of PV-positive cells (Fuchs et al., 2007). Our results indicate that synchronization during ripple oscillations is facilitated, whereas theta and gamma oscillations remain intact in PV- $\Delta$ GluR-A mice.

\section{Materials and Methods}

Transgenic mice. The PV- $\Delta$ GluR-A mice were generated as described previously (Fuchs et al., 2007). Briefly, mice expressing Cre recombinase under the control of PV promoter were bred with mice carrying a loxPflanked exon 11 of the GluR-A allele. The genetic background of PV$\Delta$ GluR-A mutants and their littermates was C57BL/6. The specific expression of Cre recombinase in PV-positive interneurons was verified by immunocytochemistry, and the cell-type-specific ablation was analyzed by double immunofluorescence (lack of GluR-A in PV-positive cells) and corroborated by electrophysiological measurements (Fuchs et al., 2007).

Electrode implantation and data acquisition. Custom-made microdrives were loaded with independently movable tetrodes (fabricated 
from $12 \mu \mathrm{m}$ stainless steel wires; Kanthal), linear silicone probes (50 $\mu \mathrm{m}$ intersite distance; Acreo $\mathrm{AB})$ or arrays of single tungsten wires $(40 \mu \mathrm{m}$; California Fine Wire Company). The electrodes were implanted under isoflurane anesthesia above one hippocampus (anteroposterior, $2 \mathrm{~mm}$; lateral, $1 \mathrm{~mm}$; ventral, $0.7 \mathrm{~mm}$ ) in control (GluR-A ${ }^{2 \text { lox }}$, PVCre, and wild type, $n=7)$ and PV- $\Delta$ GluR-A mutant $(n=7)$ mice. Control mice with the indicated genotypes did not show any difference in electrophysiological properties that were tested in vitro (Fuchs et al., 2007). Neocortical electroencephalogram (EEG) and reference electrodes were miniature stainless-steel screws in the skull. Electromyogram (EMG) electrodes were inserted in the neck muscle. Implanted electrodes and microdrives were secured on the skull with dental acrylic. All experiments were conducted in compliance with German law and with the approval of the Regierungspräsidium Karlsruhe.

The electrodes were connected to operational amplifiers (Noted B.T.) to eliminate cable movement artifacts. Electrophysiological signals were differentially amplified, bandpass filtered $(1 \mathrm{~Hz}$ to $10 \mathrm{kHz}$; MCP Plus signal conditioner; Alpha Omega), and acquired continuously at $20 \mathrm{kHz}$ (Alpha-Map; Alpha Omega). Electrodes were positioned in the CA1 stratum pyramidale guided by depth profile of ripple oscillations and unitary discharges as a reference. Recordings were performed during exploratory behavior (foraging in an open field), awake immobility, and sleep.

Data analysis. Signal processing was performed offline by customwritten Matlab (MathWorks) and occasionally by $\mathrm{C}++$ algorithms. EEG was obtained by low-pass filtering ( $700 \mathrm{~Hz}$ cutoff frequency) and downsampling to $1250 \mathrm{~Hz}$ of the wide-band signal. Hippocampal recordings with ripple oscillations of the maximal amplitude were selected. In these recordings, vigilance states (waking, SWS, and PS) were reconstructed with $10 \mathrm{~s}$ resolution as reported previously (Parmentier et al., 2002). Waking (desynchronized neocortical EEG and phasic activity in the EMG, thus primarily active waking), SWS (slow-wave activity in the neocortical EEG and decreased muscle tone), and PS (desynchronized neocortical EEG and muscle atonia) were defined on the basis of neocortical EEG and EMG activity with a reference to neocortical EEG spectral density in the $0.8-4 \mathrm{~Hz}$ band.

Theta-oscillation epochs were manually selected during waking and PS. Power spectral density was computed with the multi-taper method (window length, 1024; $[\mathrm{NW}]=3, \mathrm{~W}$ and $\mathrm{N}$ denote bandwidth parameter and taper length, respectively). For the analysis of coupling between theta and gamma oscillations, peaks of theta and of concurrent gamma oscillations were detected in $5-10$ and $35-85 \mathrm{~Hz}$ bandpass-filtered signals. Amplitudes of the peaks and interpeak intervals were computed. Positive peaks and interpeak intervals in the gamma band were assigned to the phase of the concurrent theta oscillation (obtained by Hilbert transform in 5-10 $\mathrm{Hz}$ band). Coefficient of modulation was estimated from resulting phase histograms in the following way: $\left(V_{\max }-V_{\min }\right) /\left(V_{\max }+\right.$ $V_{\text {min }}$ ), where $V_{\max }$ and $V_{\min }$ denote the maximal and minimal values of the phase histogram.

Ripple oscillations were detected as described previously (Csicsvari et al., 1999b; Ponomarenko et al., 2004) by a threshold-based peakdetection algorithm. Hippocampal EEG was filtered in the $150-250 \mathrm{~Hz}$ band, rectified, and smoothed with $5 \mathrm{~ms}$ time constant. Events with amplitude exceeding $7 \mathrm{SD}$ above noise mean for at least $15 \mathrm{~ms}$ were detected. The beginning and the end of oscillatory epochs were marked at points at which the amplitude of a ripple fell below $0.5 \mathrm{SD}$ above the noise mean. Complementary, multi-taper power spectra (window size, 1024; $[\mathrm{NW}]=1.5$ ) (Buzsáki et al., 2003) were computed for $128 \mathrm{~ms}$ epochs centered at a ripple maximal peak. SWS spectra in the frequency range of $100-200 \mathrm{~Hz}$ were normalized to the PS spectra of the same recording in the respective frequency range. Average sharp waves were computed in low-pass-filtered (cutoff at $48 \mathrm{~Hz}$ ) silicon probe recordings from stratum pyramidale and stratum radiatum using maximal peaks of ripple oscillations as triggers.

Action potentials were detected in a bandpass-filtered signal $(0.8-5$ $\mathrm{kHz}$ ). Events with the magnitude exceeding $3 \mathrm{SD}$ above mean were detected, and spike waveforms were extracted and represented by the first three principle components (Csicsvari et al., 1999b). Spike sorting was performed automatically [KlustaKwik (Harris et al., 2000)] followed by manual clusters adjustment [Klusters (Hazan et al., 2006)]. Putative py- ramidal cells and interneurons were identified from their autocorrelograms, firing rates $(<3 \mathrm{~Hz}$ for pyramidal cells and $>7 \mathrm{~Hz}$ for putative basket cells), and action potential width (Csicsvari et al., 1999b; Henze et al., 2000). Single pyramidal cells with clear refractory period ( $\geq 2 \mathrm{~ms}$ ) and single and multiunit interneurons were used in additional analysis. The quality of sorted units was further estimated by computing the isolation distance of clusters (Harris et al., 2000) and database redundancy measures. The latter, based on the similarity of the spike waveform across tetrode channels, excluded recorded units that might have been repeated in sequential recordings from the same tetrode. Cells with an isolation distance of at least 30 were included in the analysis. To isolate bursts, an arbitrary interspike interval threshold of $20 \mathrm{~ms}$ was used.

The phase of ripple oscillations was extracted by linear interpolation between waves extrema at $20 \mathrm{kHz}$ from the original signal filtered in the ripple band. Phase modulation histograms of recorded spike trains were obtained and bin-wise normalized by the deviations (if any) of underlying phase distribution from uniformity. Individual unitary histograms were smoothed with the Gaussian kernel (Csicsvari et al., 1999b). The modulation index for individual unitary phase histograms was computed as a circular vector length (obtained with the Rayleigh test).

Histology. After completion of recordings, the mice were deeply anesthetized, perfused intracardially with $4 \%$ paraformaldehyde solution, and decapitated. Brains were fixed in $30 \%$ formalin-sucrose. The brains were subsequently frozen, cut in $40 \mu \mathrm{m}$ slices, and stained with cresyl violet, and recording sites were confirmed (supplemental Fig. S1, available at www.jneurosci.org as supplemental material).

Statistical analysis. Two-way ANOVA was used to estimate significance of genotype and vigilance state-related differences. The statistical significance of single comparisons was determined by the Wilcoxon's rank sum test or, when specified, with $t$ test depending on the distribution normality (determined by Lillieforce test). Circular statistics was performed using Rayleigh and Mardia-Watson-Wheeler tests. P-values $<0.05$ were considered to indicate significance.

\section{Results}

In vivo measurements were performed in freely behaving PV$\Delta$ GluR-A mice implanted with tungsten wire-array electrodes, tetrodes, or silicone probes, and theta, gamma, and ripple oscillations during characteristic behavioral states were analyzed.

Theta and gamma oscillations during PS (Fig. $1 A$ ) and active wakefulness (data not shown) were essentially intact in PV$\Delta$ GluR-A mice. Examination of LFP power spectra did not reveal significant differences in theta $(5-10 \mathrm{~Hz})$ and gamma $(30-85$ $\mathrm{Hz}$ ) power between the genotypes in either states (data from 7 control and 7 PV- $\Delta$ GluR-A mice; for theta, $F_{(1,22)}=0.32, p \sim$ 0.57; for gamma, $F_{(1,22)}=0.54, p \sim 0.47$, two-way ANOVA). There was also no difference between genotypes in the power of fast gamma oscillations $(50-85 \mathrm{~Hz})$ during active wakefulness, PS, and SWS $\left(F_{(1,36)}=1.11, p \sim 0.30\right.$, two-way ANOVA). Modulation of gamma amplitude and gamma frequency by concurrent theta oscillations during PS and waking were similar between genotypes $\left(F_{(1,22)}=1.07, p \sim 0.31\right.$ for amplitude; $F_{(1,22)}=1.20$, $p \sim 0.29$ for frequency, two-way ANOVA). Thus, features of theta and gamma oscillations in the CA1 area were not altered in the mutant.

In contrast, the analysis of ripple oscillations revealed differences between control and mutant mice. During SWS, the power in the high-frequency band $(100-200 \mathrm{~Hz})$ was increased in PV$\Delta$ GluR-A mice (cumulative power, $4.10 \pm 0.35$ vs $5.84 \pm 0.62$ for 7 control and 7 mutant mice; $p<0.05, t$ test) (Fig. $1 B$ ). Additional analysis revealed that this alteration in the mutant resulted from an increase of the power of isolated ripples $(p<0.01$ for 5 control and $5 \mathrm{PV}-\Delta \mathrm{GluR}$-A mice implanted with low-impedance electrodes) (for all animals, see Fig. 1C). Expectedly, average ripple waveforms (Fig. 1D) also showed an increased ripple amplitude. However, neither the rate of ripple occurrence $(0.97 \pm 0.13$ 

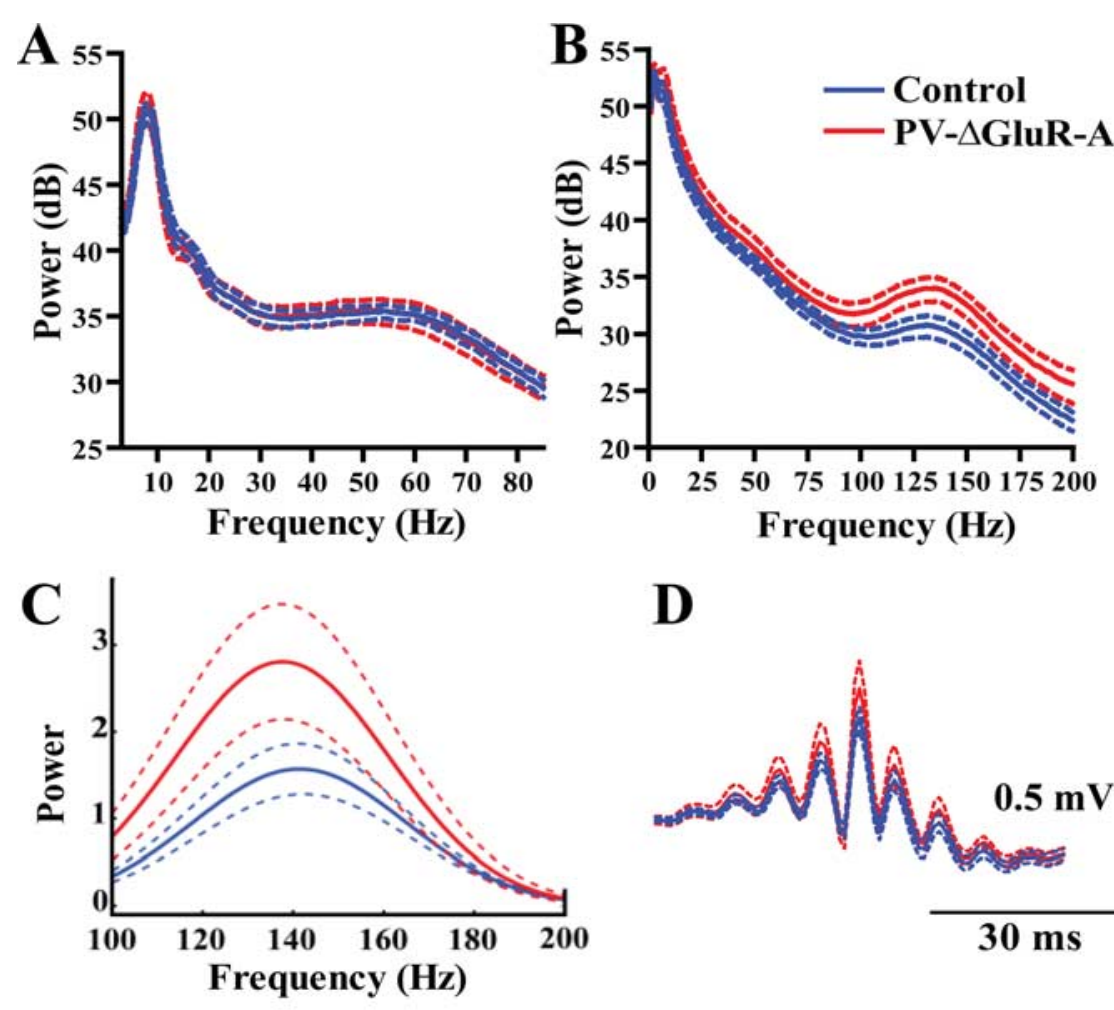

D

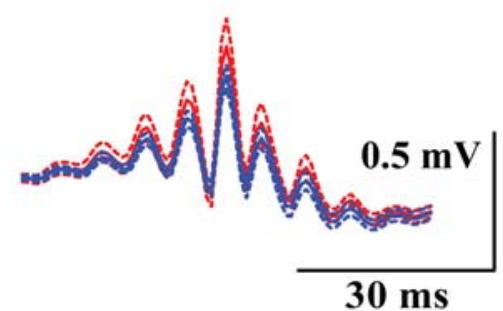

$\mathbf{E}$

Control

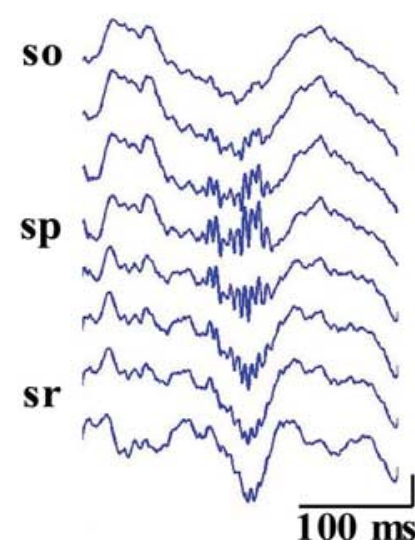

PV- $\Delta$ GluR-A F

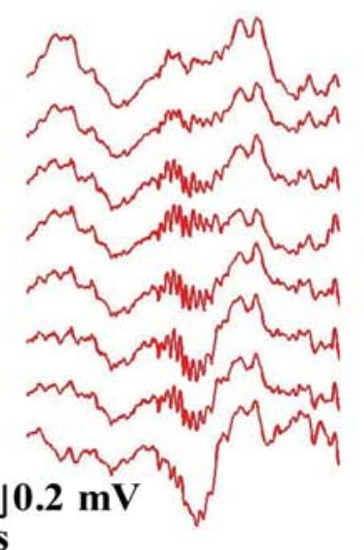

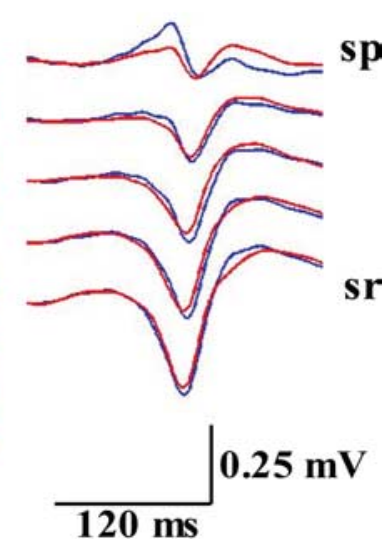

$120 \mathrm{~ms}$

Figure 1. A, Power spectra of PS episodes (mean \pm SEM of 7 control and 7 PV- $\triangle$ GluR-A mice). $\boldsymbol{B}$, Power spectra of SWS episodes (mean \pm SEM of 7 control and 7 mutant mice). PV $-\Delta$ GluR-A mice display an increased power in the high-frequency band $(100-200 \mathrm{~Hz})$. C, Mean power spectra of individual ripples (mean \pm SEM). D, Average ripple waveforms (mean \pm SEM). $\boldsymbol{E}$, Representative depth profiles of ripple oscillations obtained with silicone probes. $\boldsymbol{F}$, Average sharp wave profiles from two control and two PV- $\Delta$ GluR-A mice. Note similarity of SPW ripple profiles in the two genotypes. so, Stratum oriens; $5 p$, stratum pyramidale; sr, stratum radiatum.

$\mathrm{Hz}$ in control vs $1.33 \pm 0.19 \mathrm{~Hz}$ in PV- $\Delta$ GluR-A; $p \sim 0.14, t$ test $)$ nor ripple duration $(84.80 \pm 5.09 \mathrm{~ms}$ in control vs $92.97 \pm 5.43$ $\mathrm{ms}$ in PV- $\Delta$ GluR-A; $p \sim 0.30$ ) were altered in the mutants. The intrinsic ripple frequency estimated from intervals between ripple peaks did not differ between genotypes $(171.37 \pm 1.59 \mathrm{~Hz}$ in control and $174.86 \pm 2.14 \mathrm{~Hz}$ in PV- $\Delta$ GluR-A mice; $p \sim 0.21, t$ test). Ripples during awake immobility were consistently of lower power in both genotypes ( $p<0.05$ for controls and mutants, Wilcoxon's matched paired test) (supplemental Fig. S2 A, available at www.jneurosci.org as supplemental material), but mutants exhibited an increased ripple power during awake immobility as well $(p<0.01)$.

Possible alterations in the laminar profile of ripples and asso- ciated sharp waves in PV- $\Delta$ GluR-A mice could be excluded. In two mice per genotype, recordings were obtained with silicone probes and LFP depth profiles (obtained from stratum oriens, pyramidale, and radiatum of the CA1 area) (Fig. 1E) indicated that there was no difference between genotypes. Thus, ripples with highest amplitude were recorded in the pyramidal cell layer, and they were accompanied by sharp waves in stratum radiatum. Also, sharp-wave amplitudes were comparable between genotypes both during SWS (Fig. $1 F$ ) and awake immobility (supplemental Fig. S2 B, available at www.jneurosci.org as supplemental material). In agreement with previous reports (O'Neill et al., 2006), they tended to be smaller during awake immobility compared with SWS (supplemental Fig. S2 B, available at www.jneurosci.org as supplemental material). Hence, we can exclude differences in the site of ripple generation that might lead to the observed functional alterations in the mutant.

An increase in the amplitude of ripples could arise from an increased firing rate of individual cells or from their more coordinated rhythmic activity. To distinguish between these possibilities, we next studied unitary activity of pyramidal cells and putative interneurons. Similar average firing rates of pyramidal cells and fast-spiking interneurons in both genotypes were indicative of unaltered network excitability in PV- $\Delta$ GluR-A mice $(0.37 \pm 0.04 \mathrm{~Hz}$ for 34 control and $0.49 \pm 0.05 \mathrm{~Hz}$ for $114 \mathrm{PV}-$ $\Delta$ GluR-A pyramidal cells, $p \sim 0.7 ; 15.90 \pm$ $1.37 \mathrm{~Hz}$ for 17 control and $15.57 \pm 0.91 \mathrm{~Hz}$ for 62 PV- $\Delta$ GluR-A interneurons, $p$ $0.4)$. Furthermore, in both genotypes, pyramidal cells and interneurons fired at similar average rates during ripples $(2.32 \pm 0.47$ vs $2.41 \pm 0.39 \mathrm{~Hz}$ for 31 control and $111 \mathrm{PV}-\Delta$ GluR-A pyramidal cells, $p \sim 0.1$; and $46.85 \pm 5.60$ vs $45.23 \pm 3.61$ $\mathrm{Hz}$ for 17 control and $59 \mathrm{PV}-\Delta$ GluR-A interneurons, $p \sim 0.8, t$ test). The increase of the discharge during ripples over the average firing rate in individual cells did not differ in interneurons and was slightly but not significantly lower in pyramidal cells in the mutant $(3.02 \pm 0.32$ and $3.00 \pm 0.21$ times for control and PV- $\Delta$ GluR-A interneurons, $p \sim 0.95$; $9.10 \pm 2.65$ and $6.76 \pm 1.30$ times for control and PV- $\Delta$ GluR-A pyramidal cells, $p \sim 0.11$ ). However, the larger ripples in mutant mice were associated with an increased rhythmic discharge modulation in both pyramidal cells and, to a smaller extent, in interneurons (circular vector length, $0.83 \pm 0.05$ and $0.97 \pm 0.02$ for control and PV- $\Delta$ GluR-A pyramidal cells, $p<0.01 ; 0.92 \pm 0.11$ and $1.07 \pm 0.03$ for control and PV- $\Delta$ GluR-A interneurons, $p \sim$ 0.09) (Fig. $2 B, C$ ) (supplemental Fig. S3A, available at www. jneurosci.org as supplemental material). The better agreement of ripple LFP changes with the rhythmic discharge of pyramidal 

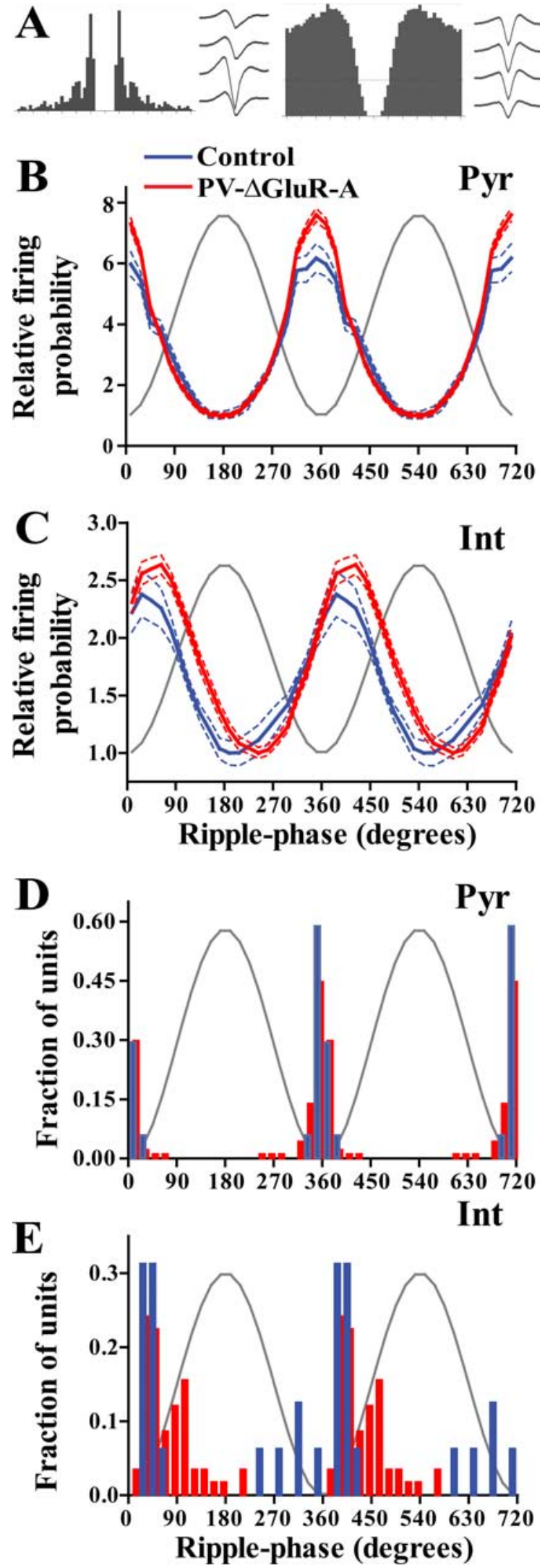

Figure 2. A, Representative autocorrelogram and average waveforms obtained from a CA1 pyramidal cell (left) and from an interneuron (right). $\boldsymbol{B}, \boldsymbol{C}$, Modulation of firing probability of pyramidal cells ( $\boldsymbol{B} ; 17$ cells from control and 94 from PV $-\Delta$ GluR-A mice) and interneurons ( $\boldsymbol{C} ; 16$ from control and 58 from PV- $\Delta$ GluR-A mice) during ripple oscillations (mean \pm SEM). The firing probability is normalized to the minimal value of the respective group. Gray sine-wave indicates a reference cycle. $\boldsymbol{D}, \boldsymbol{E}_{\text {, }}$ Histograms of preferred discharge phases of individual units. Pyr, Pyramidal cells; Int, interneurons.
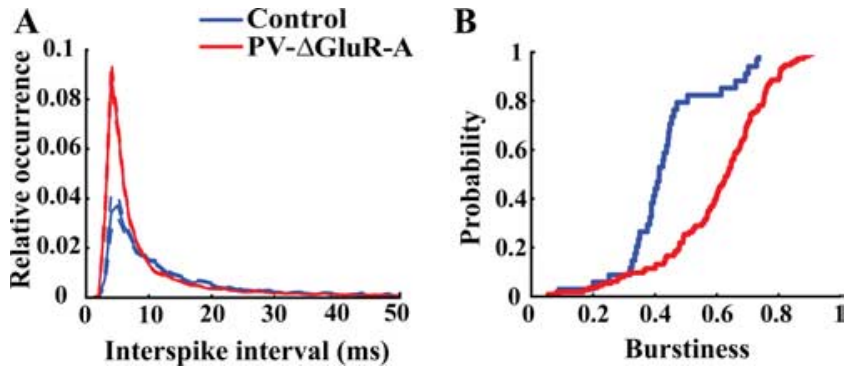

Figure 3. Increased burst firing of CA1 pyramidal cells in PV- $\Delta$ GluR-A mice. A, Average interspike interval histograms of pyramidal neurons from control and PV- $\Delta$ GluR-A mice (34 cells from control and 114 cells from PV $-\Delta$ GluR-A mice). The histograms of individual cells were normalized to the overall number of their spikes and averaged. Data are represented as mean \pm SEM. $B$, Cumulative distributions of pyramidal cell burstiness in control and PV$\Delta$ GluR-A mice. Burstiness of pyramidal neurons was computed as the ratio of action potentials within bursts over the total number of action potentials.

cells compared with that of interneurons is consistent with previous reports (Csicsvari et al., 1999a). Thus, the increased LFP ripple amplitude most likely results from enhanced rhythmic precision of the neuronal discharge rather than from increased discharge rates. We did not find a significant difference in the phase of maximal discharge probability for control and PV$\Delta$ GluR-A pyramidal cells $(p \sim 0.40$, Mardia-Watson-Wheeler test) (Fig. 2D), whereas interneurons in the mutant tended to discharge later during the cycle than those in control mice $(p \sim$ 0.09 ) (Fig. 2E). The phase delay between preferred discharge of pyramidal and interneuron cell populations was $\sim 23^{\circ}$ in control and $\sim 70^{\circ}$ in PV $-\Delta$ GluR-A mice. All units displayed a significant phase modulation by the concurrent ripple oscillations ( $p$ value of at least $<0.05$ ).

Burst discharge of pyramidal cells is at least in part regulated by the efficacy of feedback inhibition and thus might be altered in $\mathrm{PV}-\Delta$ GluR-A mice. Indeed, the mean interspike interval histograms indicate increased burst firing of pyramidal cells in PV$\Delta$ GluR-A mice (Fig. $3 A$ ). Discharge frequency in the higher range $(>50 \mathrm{~Hz})$ was increased in PV- $\Delta$ GluR-A mice (interspike intervals were $7.03 \pm 0.47 \mathrm{~ms}$ for 34 control and $5.36 \pm 0.17 \mathrm{~ms}$ for 114 PV- $\Delta$ GluR-A pyramidal cells; $p<0.0001)$. Differences between controls and mutants also resulted from the analysis of median interspike intervals during distinct synchronous network states (theta, $20.69 \pm 5.69$ and $10.46 \pm 1.19 \mathrm{~ms}$ for 30 control and 106 PV- $\Delta$ GluR-A pyramidal cells, $p<0.001$; ripples, $10.48 \pm$ $0.60 \mathrm{~ms}$ for 30 control and $9.11 \pm 0.53 \mathrm{~ms}$ for $108 \mathrm{PV}-\Delta$ GluR-A pyramidal cells, $p<0.01$ ). Thus, pyramidal cells in the mutant fire faster bursts consistent with reduced feedback inhibition. Pyramidal cells in PV- $\Delta$ GluR-A mice were more likely to fire bursts as well (the ratio of burst spikes to all spikes was $0.43 \pm$ 0.02 for control and $0.60 \pm 0.02$ for PV- $\Delta$ GluR-A pyramidal cells; $p<0.0001$ ) (Fig. $3 B$ ). This alteration was specific for pyramidal cells and was not seen in interneurons $(p \sim 0.22)$. Interspike intervals of interneurons in the two genotypes were associated with the local frequency of concurrent ripple oscillations in a similar manner (estimated from intervals between ripple peaks in the range between 4 and $7 \mathrm{~ms}: r=0.4, p<0.0001$, control; $r=$ $0.3, p<0.0001$, mutant). Concurrently with the unchanged frequency of ripples in the mutant, autocorrelations of interneurons during ripples showed maximal discharge probabilities in the ripple band (6-7 ms lags, not significantly different between genotypes, $p \sim 0.87, t$ test) (supplemental Fig. S4, available at www.jneurosci.org as supplemental material). 


\section{Discussion}

In the present study, we made use of genetically modified mice to investigate the importance of the excitatory recruitment of PVpositive cells for hippocampal oscillations. Our results reveal that ripple oscillations $(140-200 \mathrm{~Hz})$ in the CA1 area are selectively facilitated, whereas other characteristic hippocampal rhythms remain intact.

Ripple oscillations in the CA1 were shown to be associated with a transient synchronized discharge of interneurons (Buzsáki et al., 1992; Ylinen et al., 1995; Csicsvari et al., 1999b, 2000) that, based on their location and firing properties, most likely represent to a large extent PV-positive interneurons (Klausberger et al., 2003). The coordinated activity of CA1 interneurons at ripple frequency cannot directly result from external drive given the slower oscillations generated in the CA3 region (Csicsvari et al., 1999a, 2000). Hence, local synchronization mechanisms underlying ripple generation have been proposed to operate in the CA1 area (Ylinen et al., 1995; Csicsvari et al., 1999a). The discharge of CA1 interneurons can be phase reset by the discharge of CA1 pyramidal cells and/or by mutual inhibitory and electrical coupling with other interneurons (Ylinen et al., 1995; Csicsvari et al., 1999a,b, 2000). Our findings imply that the excitatory input via GluR-A containing AMPA receptors makes a limited contribution to the excitability of PV-positive interneurons during ripple oscillations.

Facilitated ripple oscillations at the LFP and cellular level in PV- $\Delta$ GluR-A mice were not accompanied by qualitative changes either with respect to the anatomical distribution of ripples and sharp waves or regarding the rhythmic pattern of concurrent neuronal discharge. Thus, physiological synchronization mechanisms are likely preserved in $\mathrm{PV}-\Delta$ GluR-A mice and operate more effectively in the setting of the reduced recruitment of interneurons by pyramidal cells. The deficient recruitment of interneurons and associated insufficient feedback inhibition during population activity can explain the facilitated high-frequency discharge of pyramidal cells. Alternatively, an increased contribution of PV-negative neurons or adjusted physiological properties of pyramidal cells might account for the findings described above. Although these concerns cannot be dismissed completely, this is unlikely given the late developmental gene ablation (at approximately postnatal week 6) (Fuchs et al., 2007), the unaltered excitable properties of non-fast-spiking interneurons (O-LM cells) and pyramidal cells in vitro (Fuchs et al., 2007), as well as the unchanged average neuronal firing rates and preserved associations between neuronal and LFP measures reported here.

Both local CA1 and distal CA3 as well as entorhinal cortical inputs provide excitatory innervation to $\mathrm{PV}$-positive cells via GluR-A- and/or GluR-D- subunit containing AMPA receptors (Baude et al., 1995; Geiger et al., 1995; Leranth et al., 1996). During SPW ripples, collective discharge of CA3 pyramidal cells drives the discharge of CA1 neurons (Chrobak and Buzsáki, 1994). There were, however, no changes in firing rates, LFP sharp waves, or fast oscillation frequency that would be indicative (Traub et al., 1996; Csicsvari et al., 1999a) of alteration in the efficacy of CA3 inputs in PV- $\Delta$ GluR-A mice. These results are also in line with our previous finding demonstrating that the excitability of fast-spiking cells after the stimulation of the CA3 area was only modestly affected and that of pyramidal cells remained intact in hippocampal slices from PV- $\Delta$ GluR-A mice (Fuchs et al., 2007). Alterations in the efficacy of entorhinal inputs during ripples were unlikely to account for the observed findings because it would also lead to changes in the probability of ripple occurrence (Isomura et al., 2006). Hence, although the GluR-A ablation is not restricted to CA1 region, our results do not support a scenario in which CA3 or entorhinal cortex would substantially contribute to the observed phenotype.

The recruitment of basket interneurons by pyramidal cells has been suggested to be essential in the generation of both gamma (Fisahn et al., 1998; Traub et al., 1998; Csicsvari et al., 2003) and ripple (Ylinen et al., 1995; Csicsvari et al., 1999b) oscillations. Apart from unlikely but possible compensatory changes after the genetic manipulation, modifications of ripple but not gamma oscillations (at least at the level of LFP) in the mutant could result from the state dependence of excitatory transmission from pyramidal cells to interneurons (Csicsvari et al., 1998, 2000). Furthermore, other network determinants of gamma and ripple oscillations (gap junctions, Draguhn et al., 1998, 2000; phasic inhibitory coupling between interneurons, Wang and Buzsáki, 1996) can differentially interact with the signaling between pyramidal cells and fast-spiking interneurons via GluR-A molecules, resulting in the preferential alterations of ripple oscillations in the mutant.

\section{References}

Baude A, Nusser Z, Molnár E, McIlhinney RA, Somogyi P (1995) Highresolution immunogold localization of AMPA type glutamate receptor subunits at synaptic and non-synaptic sites in rat hippocampus. Neuroscience 69:1031-1055.

Buzsáki G (1989) Two-stage model of memory trace formation: a role for “noisy” brain states. Neuroscience 31:551-570.

Buzsáki G, Horváth Z, Urioste R, Hetke J, Wise K (1992) High-frequency network oscillation in the hippocampus. Science 256:1025-1027.

Buzsáki G, Bragin A, Chrobak JJ, Nádasdy Z, Sík A, Hsu M, Ylinen A (1994) Oscillatory and intermittent synchrony in the hippocampus: relevance to memory trace formation. Temporal coding in the brain, pp 145-172. Berlin: Springer.

Buzsáki G, Buhl DL, Harris KD, Csicsvari J, Czéh B, Morozov A (2003) Hippocampal network patterns of activity in the mouse. Neuroscience 116:201-211.

Chrobak JJ, Buzsáki G (1994) Selective activation of deep layer (V-VI) retrohippocampal cortical neurons during hippocampal sharp waves in the behaving rat. J Neurosci 14:6160-6170.

Csicsvari J, Hirase H, Czurko A, Buzsáki G (1998) Reliability and state dependence of pyramidal cell-interneuron synapses in the hippocampus: an ensemble approach in the behaving rat. Neuron 21:179-189.

Csicsvari J, Hirase H, Czurkó A, Mamiya A, Buzsáki G (1999a) Fast network oscillations in the hippocampal CA1 region of the behaving rat. J Neurosci 19:RC20(1-4).

Csicsvari J, Hirase H, Czurkó A, Mamiya A, Buzsáki G (1999b) Oscillatory coupling of hippocampal pyramidal cells and interneurons in the behaving rat. J Neurosci 19:274-287.

Csicsvari J, Hirase H, Mamiya A, Buzsáki G (2000) Ensemble patterns of hippocampal CA3-CA1 neurons during sharp wave-associated population events. Neuron 28:585-594.

Csicsvari J, Jamieson B, Wise KD, Buzsáki G (2003) Mechanisms of gamma oscillations in the hippocampus of the behaving rat. Neuron 37:311-322.

Draguhn A, Traub RD, Schmitz D, Jefferys JGR (1998) Electrical coupling underlies high-frequency oscillations in the hippocampus in vitro. Nature 394:189-192.

Draguhn A, Traub RD, Bibbig A, Schmitz D (2000) Ripple (approximately $200-\mathrm{Hz}$ ) oscillations in temporal structures. J Clin Neurophysiol 17:361-376.

Fisahn A, Pike FG, Buhl EH, Paulsen O (1998) Cholinergic induction of network oscillations at $40 \mathrm{~Hz}$ in the hippocampus in vitro. Nature 394:186-189.

Freund TF, Buzsáki G (1996) Interneurons of the hippocampus. Hippocampus 6:347-470.

Fries P, Schröder JH, Roelfsema PR, Singer W, Engel AK (2002) Oscillatory neuronal synchronization in primary visual cortex as a correlate of stimulus selection. J Neurosci 22:3739-3754.

Fuchs EC, Zivkovic AR, Cunningham MO, Middleton S, Lebeau FE, Bannerman DM, Rozov A, Whittington MA, Traub RD, Rawlins JN, Monyer H 
(2007) Recruitment of parvalbumin-positive interneurons determines hippocampal function and associated behaviour. Neuron 53:591-604.

Geiger JR, Melcher T, Koh DS, Sakmann B, Seeburg PH, Jonas P, Monyer H (1995) Relative abundance of subunit mRNAs determines gating and $\mathrm{Ca}^{2+}$ permeability of AMPA receptors in principal neurons and interneurons in rat CNS. Neuron 15:193-204.

Gray CM, Singer W (1989) Stimulus-specific neuronal oscillations in orientation columns of cat visual cortex. Proc Natl Acad Sci USA 86:1698-1702.

Harris KD, Henze DA, Csicsvari J, Hirase H, Buzsáki G (2000) Accuracy of tetrode spike separation as determined by simultaneous intracellular and extracellular measurements. J Neurophysiol 84:401-414.

Hazan L, Zugaro M, Buzsáki G (2006) Klusters, NeursoScope, NDManager: a free software suite for neurophysiological data processing and visualization. J Neurosci Methods 155:207-216.

Henze DA, Borhegyi Z, Csicsvari J, Mamiya A, Harris KD, Buzsáki G (2000) Intracellular features predicted by extracellular recordings in the hippocampus in vivo. J Neurophysiol 84:390-400.

Isomura Y, Sirota A, Ozen S, Montgomery S, Mizuseki K, Henze DA, Buzsáki G (2006) Integration and segregation of activity in entorhinalhippocampal subregions by neocortical slow oscillations. Neuron 52:871-882.

Jensen O, Lisman JE (1996) Novel lists of $7+/-2$ known items can be reliably stored in an oscillatory short-term memory network: Interaction with long-term memory. Learn Mem 3:257-263.

Klausberger T, Somogyi P (2008) Neuronal diversity and temporal dynamics: the unity of hippocampal circuit operations. Science 321:53-57.

Klausberger T, Magill PJ, Márton LF, Roberts JD, Cobden PM, Buzsáki G, Somogyi P (2003) Brain-state- and cell-type-specific firing of hippocampal interneurons in vivo. Nature 421:844-848.

Kudrimoti HS, Barnes CA, McNaughton BL (1999) Reactivation of hippocampal cell assemblies: effects of behavioral state, experience, and EEG dynamics. J Neurosci 19:4090-4101.

Leranth C, Szeidemann Z, Hsu M, Buzsáki G (1996) AMPA receptors in the rat and primate hippocampus: a possible absence of GluR2/3 subunits in most interneurons. Neuroscience 70:631-652.
Mann EO, Suckling JM, Hajos N, Greenfield SA, Paulsen O (2005) Perisomatic feedback inhibition underlies cholinergically induced fast network oscillations in the rat hippocampus in vitro. Neuron 45:105-117.

McBain CJ, Fisahn A (2001) Interneurons unbound. Nat Rev Neurosci 2:11-23.

O'Keefe J, Nadel L (1978) The hippocampus as a cognitive map. Oxford: Oxford UP.

O’Neill J, Senior T, Csicsvari J (2006) Place-selective firing of CA1 pyramidal cells during sharp wave/ripple network patterns in exploratory behavior. Neuron 49:143-155.

Parmentier R, Ohtsu H, Djebbara-Hannas Z, Valatx JL, Watanabe T, Lin JS (2002) Anatomical, physiological, and pharmacological characteristics of histidine decarboxylase knock-out mice: evidence for the role of brain histamine in behavioral and sleep-wake control. J Neurosci 22:7695-7711.

Penttonen M, Kamondi A, Acsády L, Buzsáki G (1998) Gamma frequency oscillation in the hippocampus of the rat: intracellular analysis in vivo. Eur J Neurosci 10:718-728.

Ponomarenko AA, Korotkova TM, Sergeeva OA, Haas HL (2004) Multiple $\mathrm{GABA}_{\mathrm{A}}$ receptor subtypes regulate hippocampal ripple oscillations. Eur J Neurosci 20:2141-2148.

Traub RD, Whittington MA, Stanford IM, Jefferys JG (1996) A mechanism for generation of long-range synchronous fast oscillations in the cortex. Nature 383:621-624.

Traub RD, Spruston N, Soltesz I, Konnerth A, Whittington MA, Jefferys GR (1998) Gamma-frequency oscillations: a neuronal population phenomenon, regulated by synaptic and intrinsic cellular processes, and inducing synaptic plasticity. Prog Neurobiol 55:563-575.

Wang XJ, Buzsáki G (1996) Gamma oscillation by synaptic inhibition in a hippocampal interneuronal network model. J Neurosci 16:6402-6413.

Wilson MA, McNaughton BL (1994) Reactivation of hippocampal ensemble memories during sleep. Science 265:676-679.

Ylinen A, Bragin A, Nádasdy Z, Jandó G, Szabó I, Sik A, Buzsáki G (1995) Sharp wave-associated high-frequency oscillation $(200 \mathrm{~Hz})$ in the intact hippocampus: network and intracellular mechanisms. J Neurosci 15:3046. 